\title{
LITERATURA E POLÍTICA NA ARGENTINA: A MEMÓRIA COMO CONSTRUÇÃO EM EZEIZA, DE FABIÁN CASAS, E UMA PROPOSTA PARA A CONTEMPORANEIDADE
}

\section{TAINÁ CRISTINA COSTA LOPES}

RESUM 0: O texto literário não é somente ficção, pois capta sempre algo do social; trata-se de uma prática discursiva inserida em outras práticas, impregnada de vozes e memórias, e, por isso, é sempre contaminada pelo ideológico, pelo político, pelo histórico. Essas relações foram teorizadas por Ricardo Piglia, segundo o qual, é típico, na tradição literária argentina, tematizar o confronto entre duas vozes, com suas narrativas: a do povo e a do Estado, cujo objetivo é fazer crer em certa versão da história e justificar suas atitudes opressoras. Porém, às ficções estatais se contrapõem outras narrativas, nas quais o autor nem sempre aborda o que viu ou viveu; muitas vezes ele é o porta-voz dos relatos do povo, que circulam e se chocam com as versões oficiais, como versões possíveis cujo objetivo é não deixar que a história se apague, construindo uma memória. Esse é o caso da narrativa presente no poema “Ezeiza”, de Fabián Casas, que remete ao “massacre de Ezeiza', ocorrido em 1973, no aeroporto de mesmo nome. 0 texto foi analisado por Martín Kohan em uma aula magistral e é justamente essa análise que tomo como ponto de partida e ouso ampliar, em uma discussão sobre literatura, política e memória como processo discursivo performativo e literário, considerando que a memória construída pelo eu lírico sobre o incidente que dá nome ao poema acontece a partir do que ele viveu enquanto espectador distante, e dos relatos que ouviu de quem esteve efetivamente no massacre. Ainda assim, a memória postulada em Ezeiza é política, como uma continuação da poesia política, mas por outros meios. Considerando que, em geral, a inscrição da política na literatura se dá a partir dos registros históricos, da memória 
e da disputa de narrativas, Piglia, em texto de 2001, no qual apresenta três propostas para a literatura no novo milênio, questiona-se acerca de seu futuro e de sua função. Logo, a título de conclusão, apresento a minha própria perspectiva para a literatura e sua relevância na contemporaneidade, baseando-me na seguinte citação de Calvino: "minha fé no porvir da literatura consiste em saber que há coisas que só a literatura com seus meios específicos pode brindar".

PALAVRAS-CHAVE: literatura argentina; ideologia; política; Ezeiza; Fabián Casas

La literatura es posible porque la realidad es imposible Revista Literal, volume 1.

A literatura, tal como definida por Rancière (2000), é o espaço de partilha do sensível, espaço no qual se pode captar algo do real, mas de outra maneira, de outro lugar, a partir de outra temporalidade. Assim, o texto literário consiste não somente em uma ficção, pois capta sempre algo da ordem do social; trata-se de uma prática discursiva que está inserida em outras práticas sociais, impregnada de diversas vozes e memórias.

A escrita literária, no entanto, não tem como propósito somente "servir" à descrição do real, nem à informação por si mesma; não deve ser uma representação mimética da realidade, tal como postula o texto inaugural da Revista Literal, publicada pela primeira vez em 1973, durante o período da ditadura militar na Argentina. À época de sua fundação, a revista em questão se opunha ao paradigma literário vigente, o realismo e, no texto inaugural, "No matar la palabra, no dejarse matar por ella", critica a escrita dita "militante", questionando a suposta eficácia revolucionária da literatura, a qual define como um fim em si mesma. Por isso, negava o caráter transparente da linguagem, que prima pelo referente, pois o valor da literatura não está no que ela pode evidenciar e denunciar da realidade, mas justamente na negação de sua instrumentalização.

Desse modo, a Revista Literal evidencia que a escrita não representa o real, não está a serviço de sua mimetização; insiste-se na linguagem, na mediação que se institui com ele, afirmando a sua impossibilidade. Assim, a língua e a literatura (enquanto uso social e específico da língua) criam a realidade, mais do que a representam, como um gesto performativo e ideológico do autor. Assim, ainda que 
o posicionamento da revista e a crítica ao realismo possam parecer ir na contramão do que postulou Ranciére, eles evidenciam o estreitamento do laço entre literatura e política, principalmente durante regimes ditatoriais. Há disputas estéticas e político-ideológicas no campo literário, o que leva as identidades literárias a se corresponderem com identidades políticas nesses períodos, sobretudo no que se refere à tensão com o Estado. Logo, nesse cenário, o texto literário é contaminado pelo ideológico, pelo político, pelo histórico.

Durante décadas, Ricardo Piglia dedicou-se a pensar e teorizar sobre as relações entre literatura e política, tendo como ponto de partida a teoria marxista e o maoísmo para explicar essa articulação, à luz da luta de classes e, em um segundo momento, para fazê-lo levando em conta as relações de poder, sobretudo considerando a figura autoritária do Estado. De início, Piglia (1974) ressalta que toda a reflexão estética de Mao Tse-tung define a produção artística como resposta a uma demanda social específica, que nasce da luta de classes, as quais determinam o que é arte e a quem/para que serve. Assim, a função estética não é uma propriedade imanente, é um processo determinado pelo modo de produção e muda de um modo para outro. Segundo ele, "o fundamental do processo de produção não é tanto criar produtos neste caso 'obras de arte', mas produzir o sistema de relações, os vínculos sociais que ordenam a estrutura de significação dentro do qual a obra se faz um lugar que a condiciona e decifra" (PIGLIA, 1974, p. 120-121).

Posteriormente, o autor retoma a discussão sobre literatura e política no texto "Tres propuestas para el proximo milenio (y cinco dificultades)", segundo o qual o processo literário se constrói não mais a partir da luta de classes, mas a partir de relações de poder que culminam em uma disputa de narrativas. De acordo com ele, a tradição literária argentina nasce com o texto El matadero, de Echeverría, que data de 1838 e tematiza um confronto, em enfrentamento ao terror extremo, temática que vai se repetir ao longo da historiografia literária do país. Em geral, esse conflito se dá com relação ao Estado, tomado como figura autoritária e opressora, baseado em uma tensão entre dois tipos de narrativas: a do povo e a ficção estatal. Nesse ponto, Piglia baseia-se no que diz Paul Valéry a respeito do papel do Estado, que não funciona somente a partir de forças coercitivas, mas também por meio de formas fictícias, a partir das quais cria narrativas 
a fim de construir histórias, fazer crer numa versão da história e justificar suas atitudes opressoras e repressivas.

Ainda segundo o autor, a essas ficções do Estado, contrapõem-se outras narrativas sobre o mesmo evento, como pequenos relatos e testemunhos, que circulam socialmente, e que são, eles próprios, "o contexto maior da literatura" (PIGLIA, 2001, p.16). Nesse caso, o escritor não é aquele que enuncia, é quem ouve e registra os acontecimentos, a partir da matéria-prima da literatura, ou seja, das vozes populares. Assim, o autor nem sempre diz daquilo que viu, que experienciou factualmente, muitas vezes ele é o porta-voz dos relatos do povo que circulam e se chocam com as versões oficiais, como outras versões, versões possíveis cujo objetivo é não deixar que a história se apague. Dessa forma, enquanto o Estado diz, enquanto define suas ações repressoras como uma "metáfora narrativa” (PIGLIA, 2001, p.15), a literatura não diz simplesmente sobre o que ocorreu, ela "faz ver" a partir de seus mecanismos específicos.

Nesse ponto, Piglia nos remete à escrita de Rodolfo Walsh, uma das maiores vozes da literatura argentina, que, no seio da tradição literária do país, também enfoca a tensão e a disputa de narrativas entre o Estado e o povo. Em Operación Masacre, de 1957, Walsh nos apresenta o intelectual, sujeito letrado, que enfrenta o Estado e seu relato falso dos acontecimentos e, para se opor a isso, registra versões conflitantes, em outras vozes, de modo a fazer aparecer a verdade na versão da testemunha, que viu e sobreviveu. Assim, essas várias vozes contam uma história paralela à desarticulação do relato do Estado, dando ao escritor fragmentos da realidade.

O movimento de resgate de uma memória histórica, política, particular e contrastante por parte de Walsh repete-se em vários autores na tradição literária argentina, sobretudo nos que se voltam ao período ditatorial e a importantes marcos da história política do país. No entanto, veremos que esse testemunho, esse resgate da memória nem sempre parte de uma experiência factual. É o caso, por exemplo, dos poemas analisados por Martín Kohan na aula magistral intitulada Dos ausentes en Ezeiza (2007), na qual analisa, interpreta e discute "Ezeiza", de Fabián Casas, e "Jubileo", de Ariel Schettini. Os poemas fazem referência ao "massacre de Ezeiza", ocorrido em junho de 1973, no Aeroporto Internacional Ministro Pistarini, conhecido como Aeroporto de Ezeiza, quando Juan Domingo Perón, um dos principais nomes da política argentina, regressava ao país depois 
de quase duas décadas de exílio político e a multidão de seus apoiadores foi vítima de um ataque armado de grupos da extrema direita, no qual morreram muitas pessoas.

Diante desse contexto sócio-histórico, Kohan discute/aborda a forma como se discute e politiza a memória na Argentina. As considerações do crítico literário versam a respeito das maneiras como a relação entre literatura, política e memória se articula na interpretação de um texto literário. Levando isso em conta, tomo como ponto de partida a análise de Kohan sobre o poema Ezeiza, e ouso ampliála, a partir de uma discussão sobre a literatura e a política e sobre a memória como processo discursivo performativo e processo literário. Segue o poema:

Ezeiza

Mi primo ya no es un gigante

en el crepúsculo de esta terraza

donde estamos sentados.

Dos casas más allá, con broches en los labios

y pañuelo azul en la cabeza

una mujer cuelga la ropa.

Desde que se fue el libretista

el color whisky del pelo de mi primo

empezó a clarear

y en alguna feria americana

los jóvenes modernos

deben estar probándose

su vieja melena, sus pantalones oxford,

los suecos que yo a veces le robaba

para mirarme en el espejo...

Príncipes violentos de los setenta

¿Qué podemos hacer por ustedes?

No se convirtieron en políticos

ni se exiliaron, ni están

con dos enes en el pecho debajo de la tierra... 
Ustedes,

que se colgaron de los árboles de Gaspar Campos

Y fueron a esperar al Duce a Ezeiza,

tuvieron que soportar

que el viejo no les trajera la revolución

sino la peste.

"Pero no éramos -dice mi primo

estetas de la muerte o fanáticos del dolor.

Simplemente buscábamos Tao...”

A la gente le gusta pensar

que la vida cambia. Y muchos viven pendientes

de cosas que no le van a suceder nunca.

Ahí está la vereda cubierta de arroz

del Registro Civil; el libro donde dice:

"Antes vine como el Cordero,

ahora he vuelto como el León”.

Relatos, fábulas para un pueblo construído

de agua y de fe.

La silla de mi primo está vacía.

El viento agita los árboles en la calle.

Es cierto. Todo terminó más rápido

que un día de franco.

Después pasó el tiempo,

viajamos con las tribus del norte hacia el sur.

Algunos se reprodujeron.

Otros aprendimos que el miedo

es la distancia que existe

entre el dolor y la nada.

Yo crecí y me convertí en el líder.

En cuanto al Guerrero del camino,

nunca más lo volví a ver. 


\section{Ahora él vive}

sólo

en mi memoria.

(CASAS, 2003)

A análise de Kohan tem como início a explicação de que nenhum dos dois autores, Casas nem Schettini, ambos nascidos na década de 1960, esteve presente no massacre em Ezeiza, embora tenham escrito sobre o episódio. Assim, nenhum deles escreve a partir da perspectiva de quem esteve ali, ou seja, não são testemunhas oculares e factuais do acontecimento; escrevem, nas palavras do crítico literário, justamente "porque não estiveram ali” (KOHAN, 2007, p.9). Então, sua escrita não consiste em um relato, um testemunho ou um registro político, mas, ainda assim, os poemas são definitivamente textos políticos, expulsando a ideia de que para escrever sobre um acontecimento seja necessário estar presente.

O poema de Casas, no qual centro minhas considerações, narra uma cena na qual dois primos estão sentados em um terraço e aquele que coincide com o eu-lírico expressa uma mudança do olhar que tinha em relação ao primo mais velho: "Mi primo ya no es un gigante”. Esse verso recupera não só esse olhar, que passa, tal como ressalta Kohan, de um olhar infantil para uma visão a partir da idade adulta, mas também atesta a passagem do tempo, que também se faz ver nos versos "el color whisky del pelo de mi primo / empezó a clarear”; ou seja, há a referência, aqui, a um homem que envelheceu. Na segunda e na terceira estrofes, o eu-lírico faz referência aos anos setenta, inclusive com alguns de seus símbolos - "su vieja melena, sus pantalones oxford" - e a um "ustedes" que, conforme o autor, remete à cena da matança em Ezeiza e aos seus autores, incluindo o primo, a quem nenhuma consequência se aplicou, hipótese confirmada pelos versos que vêm em seguida: "no se convirtieron en políticos / ni si exilaron, ni están / con dos enes en el pecho bajo la tierra...” Esses versos, como que interpelando os algozes, dentre os quais aquele que não é mais um gigante, são completados pelos versos da quarta estrofe, que fazem referência a Ezeiza, elipticamente ao episódio do massacre.

O poema transfigura o passado da matança dos peronistas em 1973 numa cena cotidiana, já no século XIX, na qual o eu-lírico olha para o passado e entende a história, ao contrário do que parecia fazer quando criança, e faz ver que o episódio e a imagem do primo já são só memória, quando traz, ao final, os versos “yo 
crecí y me convertí en líder. / En cuanto al Guerrero del camino, / nunca más lo volví a ver./ Ahora él vive / sólo / en mi memoria.

Assim, essa memória não é a de quem esteve em Ezeiza naquele junho de 1973, mas a memória de quem ouviu relatos, de quem soube do ocorrido por parte de outra pessoa, ou seja, é a memória de quem estava ausente. Memória que só termina de ser completada em um passado mais recente ou no presente do encontro entre os primos, no qual o olhar de criança se perdeu, como aponta Kohan. Essa memória, segundo o crítico, é carregada de falta de crença naquilo que foi um dia uma ilusão política (KOHAN, 2007, p. 13).

Há outros elementos e referências na análise de Kohan, inclusive questões linguísticas e de recursos poéticos, mas o que me interessa acrescentar a ela é como, aqui, esse autor e esse eu-lírico funcionam a modo de quem enuncia, sim, mas a partir do que ouvem de outras vozes, de versões alternativas, como pensa Piglia. No caso específico do poema, opera-se a partir de versões que se contrapõem às vozes de "ustedes”, ou seja, daqueles que não morreram no massacre, daqueles que o provocaram, personificando a figura do Estado autoritário e opressor.

Assim, a memória explorada no poema não é a memória de quem diz daquilo que viu, do que experienciou, mas uma memória construída a partir de fragmentos da história, de diversas vozes, e que funda uma realidade quase como em um ato performativo de linguagem. O eu-lírico tem o acontecimento na memória porque diz que o tem. De qualquer forma, a memória postulada em Ezeiza é uma memória política, como uma continuação da poesia política, de acordo com Kohan, mas por outros meios: "não os da presença, da representação, do testemunho, da memória histórica, da política das ruas, mas a política da ausência, do simulacro, da contemplação, da memória do presente" (KOHAN, 2007, p.17).

Logo, o que Casas constrói em seu poema é semelhante ao que faz o narrador de Operación Masacre, obra em que a contraficção estatal se contrapõe à voz da testemunha, de quem sobreviveu para narrar. Casas, por sua vez, também explora uma narrativa alternativa, mas a partir de uma experiência que o eu-lírico viveu indiretamente e de uma memória que ele criou a partir da vivência do primo e da convivência com ele. No caso de Walsh, Piglia ressalta que os vencedores escrevem a história escrita e que ouvir as vozes populares, das testemunhas, é desmontar e desconstruir a história escrita, a história oficial. 
Dentro da perspectiva marxista, como já dito, as produções artísticas e até mesmo os acontecimentos são determinados pelas condições históricas e materiais específicas da época e de cada classe e, no caso da literatura, Piglia (2001) ressalta que o trabalho literário tem como objeto a vida concreta do povo, a luta de classes e as relações sociais. Em Walsh, de acordo com o crítico, é nessa luta política, na desigualdade social e no resgate à voz popular que se dá o acesso à verdade.

Nesse sentido, os relatos populares são, para ele, a principal matéria de produção literária, como versões alternativas às narrativas do Estado, as quais podemos inferir que não consistem em produções literárias. Embora tenham uma função específica, são autoritárias, opressoras e, portanto, não se voltam para o social. Assim, os relatos populares são, sob certo aspecto, a literatura "de verdade”, em oposição à ficção estatal. A partir disso, a prática do povo, diz ele, “cria condições de uma literatura revolucionária. Em sua atividade concreta, as massas vão produzindo não só uma nova sociedade, mas também, e ao mesmo tempo, uma nova cultura e uma nova arte" (PIGLIA, 2001, p.131).

Considerando que, em geral, a inscrição da política na literatura se dá a partir dos registros históricos, da memória e da disputa de narrativas, em seu artigo “Tres propuestas para el proximo milenio (y cinco dificultades)”, Piglia questiona-se acerca do futuro da literatura e sua função. Cabe nos perguntarmos se a tradição literária de tematizar o confronto, a circulação de narrativas do povo a fim de fazer frente à ficção do Estado, por exemplo, manter-se-á no futuro. Com base nesse tipo de questionamento, o autor postula três propostas para o novo milênio.

A primeira delas é que existe uma verdade histórica e essa verdade não é direta, não é algo dado, surge da luta e da confrontação, das relações de poder (PIGLIA, 2001). Ao contrário do que faz em Mao Tse-tung: Práctica estética y lucha de clases, ele não menciona a luta de classes, pois as relações de poder se dão entre povo e Estado e se evidenciam na disputa de narrativas, como já dito. Assim, se a proposta é que há uma verdade histórica, e se a literatura consiste nos relatos populares como contraficção ao Estado, podemos inferir que a consequência dessa proposta seria a valorização das narrativas alternativas e, sob certo aspecto, marginais. 
A segunda proposta diz respeito à noção de limite, ou seja, à impossibilidade da linguagem expressar diretamente essa verdade. De acordo com Piglia (2001), no caso da literatura argentina - e acredito que também é o caso dos demais países que viveram ditaduras - a experiência do horror é tão intensa que parece estar além da linguagem; parece haver um limite, um ponto do qual parece impossível se aproximar. Segundo ele, "a literatura mostra que há acontecimentos que são muito difíceis, quase impossíveis de transmitir e que supõem uma relação nova com os limites da linguagem" (PIGLIA, 2001, p.18). Mas a literatura desafia os limites da linguagem, a sua incompletude, a impossibilidade da linguagem dizer tudo, porque o importante não é dizer, é "fazer ver”, é mostrar o que não se pode dizer. Nesse sentido, há um deslocamento: dá-se voz a um outro que fala de sua realidade, ou seja, há um distanciamento com relação à própria palavra, em direção a outra enunciação, e, assim, transmite-se a experiência, como algo que está muito além da simples informação.

Esse movimento está presente, por exemplo, nos casos em que a enunciação cria ou resgata uma memória tal como o faz o poema de Fabián Casas, Ezeiza, no qual o eu-lírico fala de uma experiência que não é a sua - pelo menos não diretamente -, de modo que o relato se desloca até uma situação concreta, na qual a memória não é resultado da recordação, de uma experiência factual, mas é uma construção discursiva que coloca um outro no espaço de uma enunciação pessoal. De acordo com Piglia, são essas memórias, enquanto versões alternativas da história, que consistem na verdade, contrariando a memória e o discurso autoritário e opressor. Assim, "a verdade tem uma estrutura de ficção onde outro fala. Há que se fazer da linguagem um lugar para que o outro possa falar" (PIGLIA, 2001, p. 19). A literatura, seria, dessa maneira, o lugar no qual sempre é outro que fala.

Por fim, o escritor postula uma terceira e última proposta para o novo milênio, ao dizer que a literatura atua, de forma definitiva, sobre um estado de linguagem e, por isso, a dimensão social está sempre na linguagem. Isso quer dizer que o discurso dominante sobre a literatura, aquele que preza pelos aspectos econômicos, produz livros escritos no que o autor chama de "língua privada", a que apaga o rastro da linguagem social. Diante disso, acredito que é preciso resgatar a "língua social", aquela que produz a verdadeira literatura, os discursos e versões outras, contadas por outras vozes, que não as dominantes, que não as do discurso oficial. Porque este se limita à dimensão informativa, que é incompleta e limitada. 
E, por fim, concluo com uma citação - ainda e novamente - de Piglia (2001, p. 11), retomando Calvino, que tomo como minha proposta para a contemporaneidade: "minha fé no porvir da literatura consiste em saber que há coisas que só a literatura com seus meios específicos pode brindar".

\section{REFERÊNCIAS}

CASAS, Fabián. Oda. Buenos Aires: Libros de Tierra Firme, 2003.

GARCÍA, Germán Leopoldo et al. No matar la palabra, no dejarse matar por ella. In: ALBA, Alberto (Ed.). Revista Literal, Buenos Aires, Ediciones Noé, n. 1, pp. 5-13, nov. 1973.

KOHAN, Martín. Dos ausentes en Ezeiza (poesía y política en el nuevo siglo). Cuadernos de Recienvenido, São Paulo, 20, 2007.

PIGLIA, Ricardo. Mao Tse-tung: Practica estética y lucha de clases. In: SOLOVEV, Z. J. et al (Eds.). Literatura y Sociedad. Buenos Aires: Tiempo contemporáneo, 1974. . Tres propuestas para el próximo milenio y cinco dificultades. Revista Casa de las Américas, n. 222, Cuba, ene.-mar. 2001, pp. 11-20.

RANCIÈRE, Jacques. A partilha do sensível. São Paulo: Editora 34, 2000. 